\title{
FALAS SOBRE GÊNERO E SUA RELAÇÃO COM A MÍDIA ${ }^{1}$ \\ SPEECHES ON GENDER AND ITS RELATIONSHIP WITH THE $M E D I A$
}

Cláudia Lago ${ }^{2}$

Escola de Comunicações e Artes da USP

\section{Resumo}

$\mathrm{O}$ artigo analisa os discursos sobre gênero nos meios de comunicação, os quais se projetam a partir de uma normatividade binária e discriminatória introjetada na sociedade, bem como seus efeitos atuais.

Palavras-chaves

Gênero. Mídia. Society

Abstract

The article analyzes the discourses on gender in the media, which are projected from a binary and discriminatory normativity introjected in society, as well as their current effects.

Keywords

Gender. Media. Society

\section{O GÊNERO A PARTIR DO COTIDIANO}

${ }^{1}$ Este texto é produto das discussões e interlocuções realizadas dentro da linha de pesquisa Alteridade, subjetividades e estudos de gênero em narrativas não ficcionais, do grupo de pesquisa AlterGen, do CNPq, da ECA/USP. Não seria possível sem o diálogo constante com minhas orientandas Elisa Canjani, Evelyn Kazan, Manuela Thamani e Natália Sierpinski, a quem agradeço imensamente pelas contribuições constantes e olhares amplos. ${ }^{2}$ Cláudia Lago é professora da Escola de Comunicações e Artes da Universidade de São Paulo. 
Recentemente estive duas situações de trabalho coletivo, em que um tipo de atitude se repetiu. $\mathrm{O}$ primeiro, um seminário de pesquisadores/as para discutir a questão do campo das ciências humanas e sociais em relação aos desmontes do sistema de pesquisa. Quando cheguei atrasada em função da quantidade de tarefas, o que é extremamente comum se pensarmos nas lógicas de atribuição ao feminino, fui inserida em uma das equipes de trabalho que estavam discutindo estratégias possíveis. Os grupos tinham mulheres e homens, em proporções variadas. Ao nos reunirmos em plenária em um momento seguinte, uma amiga comenta: estávamos em um grupo só com mulheres, quando chegou um único homem tivemos que gastar horas de discussão para convencê-lo de tudo o que já tínhamos acertado.

Bem, este é um relato de terceiros, então passo ao meu relato próprio, em que a mesma situação se repete. Como presenciei, posso apontar outras questões. No caso da reunião na qual fui testemunha, por assim dizer, também estávamos divididos/as em grupos para pensar estratégias. Desta feita, o objetivo era pensar como trabalhar com pessoas do campo conservador no Brasil, para tentar uma interlocução que pudesse contrapor as narrativas da extrema direita. Eram dois grupos, um que encabeçava a discussão tema do evento, com um número maior de pessoas, muitas mulheres, mas também a presença de vários homens. O segundo grupo, do qual fiz parte, deveria pensar a questão das estratégias de comunicação, e chegamos a apontar, mesmo que bem tangencialmente, como éramos pensados em termos de grupo meio, em vez de grupo fim. Neste grupo, eram oito mulheres e um homem. Coincidentemente repetimos as estratificações que são observadas em todas as áreas, que genereficam 
a partir do masculino o que é "sério", "final", etc. E que generificam a partir do feminino o que é menos importante. Mas isto não é a principal questão à qual desejo me ater.

Sem consciência desta separação, depois de várias discussões, a grande maioria do grupo elegeu um determinado objeto e uma determinada abordagem. Mas não conseguimos avançar porque o único homem do grupo não concordou nem com o objeto nem com a abordagem.

A partir daí toda a discussão se tornou, para mim, um experimento etnográfico, de observação. Ao mesmo tempo, não consegui deixar de pensar em uma relação com as mídias, no caso o cinema: estávamos encenando uma paródia de um filme, éramos Oito mulheres e um segredo. Neste filme, continuação da franquia Ocean ${ }^{3}$, oito mulheres se reúnem para um roubo extraordinário e, como os filmes anteriores da franquia, em planos que envolvem motivações e estratégias que só ficam claras no final da narrativa - mesmo para todas integrantes do grupo e, especialmente, para quem vê o filme.

Lembrei do filme não apenas pela coincidência das oito mulheres diversas em idade e outros marcadores, mas especialmente pela presença de uma percepção disponível para nós, mas completamente velada para o homem da equipe: sua incapacidade de perceber-se em um modus operandi masculino de relação com as mulheres ali presentes, mesmo quando toda a discussão girava em torno da necessidade de colocar-se no lugar do outro.

\footnotetext{
${ }^{3}$ A alusão é a de Ocean’s 8 (traduzido no Brasil como Oito Mulheres e um Segredo) filme resultante da franquia Ocean, que envolve grupos (as primeiras edições só de homens), envolvidos em assaltos mirabolantes e com "segredos" revelados apenas ao final.
} 
Quando falo deste modus, é importante pontuar que não parto de uma perspectiva essencializada da questão: não somos mulheres, tornamo-nos mulheres em um complexo sistema de introjeção da exterioridade e extrojeção da interioridade (BOURDIEU, 1990) e também não somos homens, tornamo-nos homens pelo mesmo tipo de processo.

Mas o que significa isso? No caso específico, tínhamos oito pessoas em um grupo que concordaram com um encaminhamento e uma pessoa que não concordou. E, em um comportamento típico de quem está acostumado a um entitlement de gênero ${ }^{4}$, retornou a seu ponto de vista seguidas vezes, até que, ao ver que não conseguia convencer a quase totalidade do grupo, declarou que iria especificar sua posição própria, enquanto minoria (sic) na plenária geral posterior dos dois grupos.

Podemos pensar que este é um comportamento particular de uma pessoa teimosa em uma particular situação. E não estaríamos errados/as, mas perderíamos as nuances das relações generificadas. Será que se o contrário acontecesse - uma mulher teimosa em um grupo de oito homens - o resultado seria idêntico? E, se fosse o caso, será que os oito homens se disporiam a gastar mais de 40 minutos tentando convencer, apaziguar, esta mulher teimosa?

\footnotetext{
${ }^{4}$ A palavra não tem um sinônimo em português, mas pode ser traduzida pela crença arraigada de alguém de quem tem o merecimento de tratamento especial, ou o direito inerente a algo. Nesse sentido, indica a ideia arraigada de sujeitos construídos como homens de que têm direitos de fala e determinação do mundo à sua volta. Sensações de direitos tão arraigadas que não são nem sequer problematizadas. E que sujeitos mulheres, por sua vez, não possuem.
} 
Porque o investimento para esclarecer, explicar, tentar convencer, realizado de formas variadas pela maior parte das mulheres envolvidas, foi intenso. Isso sem mencionar a aceitação, sem (merecidas?) respostas diretas a frases condescendentes por parte do sujeito homem, indicando que o conjunto das mulheres "não entendia" as propostas (e não que não concordava...).

$E$, se pensarmos que esta é uma situação isolada, retirada de um contexto, talvez percamos de vista as ações recorrentes envolvendo, inclusive em ambientes de trabalho com viés progressista, problemas de gênero, palpáveis, mesmo que veladas pelos sistemas de naturalização.

Situações persistentes e que se conectam de uma forma ou de outra a problemas bem mais graves relacionados às hierarquias de gênero que estabelecem padrões de normatividades excludentes e que, na ponta, explicam os altos índices de feminicídio, violência de gênero, transfobia e outros que o Brasil ostenta tão acintosa e vergonhosamente ${ }^{5}$. Situações recorrentes que também têm que ser entendidas a partir de outras lógicas, que questionem não apenas essa cultura que parece grudada ao "ser homem" ou ao "ser mulher", mas que aponte para atravessamentos outros e coloquem em xeque as perspectivas essencialistas binárias com as quais tendemos coletivamente a pensar o mundo.

5 Sobre estes dados, matéria recente apresenta e contextualiza: https://g1.globo.com/monitor-da-violencia/noticia/2019/03/08/dados-de-violenciacontra-a-mulher-sao-a-evidencia-da-desigualdade-de-genero-no-brasil.ghtml Ainda sobre dados, vale a matéria do Gênero e Número: http:/ / www.generonumero.media/transfobia11-pessoas-trans-sao-agredidas-a-cada-dia-no-brasil-2/ 


\section{UM POUCO SOBRE GÊNERO E MÍDIA}

Os dois exemplos iniciais ligam e nos lembram que, independente de nossas boas intenções, estamos todos/as imersos em sistemas baseados no gênero, que constroem o masculino e o feminino como categorias complementares e auto excludentes, que formam sistemas simbólicos e práticos que hierarquizam o mundo e as pessoas do mundo a partir de sua relação com estas categorias, sistemas que, apesar de suas diferenciações sociais e históricas, tendem a valorizar sobremaneira o masculino em detrimento do feminino ${ }^{6}$. Assumindo aqui que, como nos pontua Scott, "(1) o gênero é um elemento constitutivo de relações sociais baseadas nas diferenças percebidas entre os sexos e (2) o gênero é uma forma primária de dar significado às relações de poder (1995, p.86), também assumimos com a autora que o gênero constitui as relações sociais, significando as relações de poder, em uma relação direta com representações simbólicas e com dispositivos que regulam e orientam estas representações. Continuando a definição, Scott aponta que estão relacionadas ao primeiro ponto: representações simbólicas; sistemas normativos (como discursos médicos, jurídicos, religiosos, etc), que determinam os significados dos símbolos, colocando-os em uma oposição binária fixa que define o que é ser homem e ser mulher; implica em uma concepção de política e de organização social; e faz parte da constituição da identidade subjetiva. Em relação ao ponto dois, a autora ressalta que o gênero é chamado para legitimar e chancelar ações que com ele não

\footnotetext{
${ }^{6}$ Pierre Bourdieu (2019) descreve bem estas relações sociais hierarquizadas que privilegiam o que se refere às categorias do masculino.
} 
têm relação, ou seja, as relações políticas também são referidas ao gênero quando, por exemplo, os dominantes se colocam no polo masculino, caracterizando os dominados dentro do polo feminino ${ }^{7}$

Como espaços de circulação das representações simbólicas e relacionado aos sistemas normativos, a mídia ocupa um lugar essencial na relação com o gênero. É, pois, nesse contexto que pode ser pensada como uma importante tecnologia de gênero, (LAURETIS, 1994), ou seja, um conjunto de mecanismos que movimentam técnicas, procedimentos, narrativas, práticas que atuam para constituir sujeitos generificados a partir de lógicas específicas, heterossexistas. E, se pensarmos na centralidade dos sistemas midiáticos na constituição das subjetividades na contemporaneidade, podemos imaginar o potencial generificador que têm a mídia.

No entanto, é importante refletir sobre o que estamos falando quando nos referimos à mídia. Há uma tendência a pensá-la a partir de um viés frankfurtiano ${ }^{8}$, ou seja, a mídia como um bloco homogêneo responsável pela transmissão de signos/discursos que tem como único objetivo o reforço do status quo, reforçando os estereótipos. No caso do universo que envolve gênero, reforçando perspectivas que constroem um mundo masculino, com identificação

\footnotetext{
${ }^{7}$ Um exemplo desta relação seria a dos colonizadores que, em cartas se referem ao território colonizado como feminino, com metáforas de submissão.

${ }^{8}$ Sobre a Escola de Frankfurt e suas proposições, ver RUDIGER, Francisco. As Teorias da Comunicação. Porto Alegre: Penso, 2011.
} 
direta ao gênero (cisgênero), e branco ${ }^{9}$, para citar apenas alguns dos marcadores presentes.

Assim, tendemos a enfatizar a mídia a partir de um único lugar de produção de conteúdo e com uma capacidade quase onipresente de constituição de subjetividades, em um processo linear de produção de mensagens e incorporação destas por parte dos receptores: não pensamos que existem vários meios, cada qual com suas linguagens, campos de produção e relações com os receptores a partir de perspectivas específicas. Ao mesmo tempo é necessário pontuar que, ao tratarmos de mídia, não estamos nos referindo apenas aos meios em si, mas a todo o complexo que envolve a produção e circulação destes meios.

Dito isso, importante frisar que a mídia, da mesma forma que outras tecnologias de gênero (como o sistema jurídico, por exemplo) tende a enfatizar a lógica heterocisbrancomasculina hegemônica, mesmo em um processo que não é homogêneo. Existem fissuras que podem contrapor agentes com disposições distintas e discursos outros, bem como produtos midiáticos alternativos. Além disso, mesmo em relação às narrativas identificadas com as normativas hegemônicas, são feitas pelos receptores outras leituras, além das que aderem ao proposto, existem leituras negociadas e mesmo contrárias às propostas pelas mensagens veiculadas (HALL, 2015).

Por outro lado, também a mídia é apropriada por sujeitos e grupos discriminados para se fazerem ouvir. Por exemplo, se

9 De agora em diante identificada como uma perspectiva heterocisbrancomasculina normativa. 
pensarmos na proposta de uma quarta onda do feminismo ${ }^{10}$, como problematiza Hollanda (2018), vemos que ela é profundamente relacionada à propagação das mensagens, atuações e movimentações nas e a partir das mídias sociais, com movimentos massivos como foi o \#metoo internacionalmente e o \#primeiroassedio no Brasil.

No entanto, antes de nos aventurarmos no campo das possíveis fissuras, é necessário pontuar minimamente as recorrências nas construções das narrativas difundidas pela mídia e que, decididamente, a colocam no polo da defesa intransigente da perspectiva heterocisbrancomasculina. E que possuem um grande poder de inscrição, já que a recorrência é responsável pelas naturalizações das perspectivas - o que explica o porquê de termos que insistir na presença e difusão de narrativas e representações outras.

Não é possível no escopo deste texto discutir e apresentar as nuances da relação da mídia com a propagação das normativas heterocisbrancomasculina, até porque existem componentes diversos conforme o sujeito que está sendo representado e/ou invisibilizado. Para efeitos de ilustração, vou ater-me, mesmo que resumidamente, na relação dessas narrativas com sujeitos mulheres, pontuando que não há um sujeito mulher único, universal. Existem mulheres, sempre no plural, constituídas a partir de raça, classe, origem, idade, e outros marcadores. No entanto, a mídia tende a universalizar e essencializar os sujeitos mulheres. Esta é uma das

10 A discussão sobre as ondas do feminismo é vasta com vários autoras/es. Uma contextualização crítica pode ser observada em HEMMINGS, Clare: Contando estórias feministas (disponível em: http://www.scielo.br/pdf/ref/v17n1/a12v17n1) 
primeiras observações a serem feitas se pensarmos na constituição dessas narrativas.

Se pensarmos nas narrativas ficcionais, por exemplo, veremos que elas em geral atêm-se a certos traços importantes que enquadram as mulheres de forma nitidamente generificada. Boa parte dos produtos, sejam eles filmes, novelas, séries, quadrinhos, ou mesmo propagandas, colam às mulheres traços de caráter relacionais - são elas que estão envolvidas e são constituídas enquanto sujeitos a partir das relações afetivas (não são sujeitos para si, são sujeitos para o outro). Além disso, há geralmente uma lógica que relaciona as mulheres a um ideal de amor romântico (nem é preciso dizer que heterossexual), que é, em última instância, responsável pela felicidade desses sujeitos. Sem este as mulheres são incompletas e infelizes. Por mais que sejam retratadas como "empoderadas", este empoderamento é facilmente dispensado em prol da verdadeira vocação e desejo: o amor por um homem, a necessidade de constituir família. Frequentemente, inclusive, mulheres que não têm esta vocação são construídas como as vilãs (lembram da Cruela Cruel, dos Dálmatas?). Além disso, mulheres geralmente são enquadradas na ficção relacionadas ao espaço doméstico - reafirmando a clássica divisão do público para o masculino e do privado para o feminino, sem falar na ideia naturalizada de que todo o cuidado (care) social é responsabilidade das mulheres ${ }^{11}$.

Relacionado ao ciclo do amor romântico, os sujeitos mulheres nas ficções não se relacionam entre si, a não ser - e especialmente - quando estão em disputa por um homem. Esta 
recorrência é tão intensa que, em 1985, Alison Bechdel em um quadrinho Dykes to Watch Out For, propôs um teste para investigar a maneira como as mulheres são enquadradas em filmes. As regras do teste são simples, o filme: 1) tem pelo menos duas mulheres identificadas pelo nome? 2) estas mulheres falam entre si? 3) sobre algo que não seja um homem? Caso sim, o filme "passa" no teste. Caso não...12.

Todos estes enquadramentos apontam para um outro aspecto, fundamental se pensarmos nos enquadramentos dos sujeitos mulheres na mídia: estas estão geralmente a serviço de um olhar para o masculino e, portanto, são prioritariamente objeto para a atração, o que relaciona-se à sexualização dos corpos femininos e na ênfase nos aspectos da beleza - reproduzindo aí os padrões normativos desta beleza também (mulheres brancas, magras, jovens...).

Os exemplos disto são muitos, mas nada me parece tão eloquente quanto a chamada "espinha quebrada", uma forma corriqueira de desenhar mulheres em quadrinhos de super-heróis. É uma técnica que consiste em mostrar, em um mesmo quadrinho, a bunda e os peitos da mulher desenhada, (sempre excessivamente volumosos). Como o nome diz, este tipo de enquadramento só seria possível se a espinha da figura estivesse, literalmente, quebrada - o que me parece uma ótima ilustração pela perversidade contida no próprio nome da técnica, amplamente utilizada.

Passando para o campo da não ficção, as produções que guardam uma relação indicial com o mundo vivido, e onde se 
enquadram os produtos jornalísticos, temos alguns outros fatores a considerar, que não necessariamente excluem perspectivas já apresentadas na ficção.

Segundo o último monitoramento de mídia ${ }^{13}$, realizado em 2015, mulheres são unicamente $24 \%$ das personagens que aparecem na mídia, repetindo os números do monitoramento anterior, realizado em 2010. Mulheres aparecem nos noticiários como especialistas em proporção bem inferior aos homens: América do Norte (32\%), Caribe (29\%) e América Latina (27\%). A probabilidade das mulheres aparecerem como vítimas de violência doméstica é de $27 \%$, expressivo aumento para o monitoramento anterior, em que eram 6\%. Das notas informativas disseminadas nos jornais e programas informativos em Rádio e TV, apenas $37 \%$ são reportados por mulheres, sendo que estas são geralmente jovens. Dos programas de rádio e TV, $41 \%$ e $57 \%$ respectivamente são apresentados por mulheres. Aqui cabe uma consideração. Estes dados, que aparentemente indicam um crescimento mínimo da presença de mulheres, também podem indicar um viés de gênero. Como indica um entrevistado de pesquisa anterior ${ }^{14}$, as mulheres são boas para apresentar telejornais porque são fisicamente mais interessantes, ou seja, a questão da visibilidade estética parece ser um componente para este aumento de exposição.

O que os monitoramentos e pesquisas sobre a relação mulheres e narrativas não ficcionais apontam é uma recorrência das

\footnotetext{
${ }^{13}$ In: http://whomakesthenews.org/gmmp/gmmp-reports/gmmp-2015-reports

${ }^{14}$ In GUDIPATY, N.;RAMAPRASAD, J. ; PASTI, S. ;LAGO, Cláudia; LI, X. ; RODNYGUMEDE, Y. . Gender: towards equality?. In: Pasti, Svetlana; Ramaprasad, Jyotika. (Org.). Contemporary BRICS Journalism. 1ed.New York: Routledge, 2018, v. 1, p. 104-129
} 
divisões hierárquicas de gênero. Em todos os níveis, com na ocupação de postos de comando, geralmente por homens, mesmo quando o campo é majoritariamente composto por mulheres. É o caso, por exemplo, do jornalismo no Brasil, em que $64 \%$ dos postos são ocupados por mulheres, brancas e jovens, mas não os de comando ${ }^{15}$. Ou na escolha majoritária de homens para fontes das matérias, a não ser quando estas se referem à esfera privada, quando daí aparecem as mulheres. Um exemplo que me vem à mente é o de uma reportagem sobre aborto, realizada com entidades que trabalham com a temática enquanto uma necessidade dentro de políticas públicas e que, ao dar voz a essas entidades, seleciona um homem, e não uma mulher, entre o contingente disponível para falar do tema. Isto sem falar nos enquadramentos que reificam e naturalizam as binaridades de gênero. A compreensão de que este modo de operar é extremamente danoso em relação à proposta de igualdade de gênero (relacionada, por sua vez, à necessidade de enfrentamento das desigualdades sociais) é tão perceptível que a ONU entende que os meios de comunicação devem combater preconceitos e discriminações e criar mecanismos de difusão para erradicar esta desigualdade, sendo fundamentais na relação com o tripé redistribuição, representação e reconhecimento, necessário para este enfrentamento. A perspectiva foi firmada em duas de suas importantes conferências, a Convenção Belém do Pará (1994) e a Conferência de Beijing (1995), que define o conceito de gênero como parte da agenda internacional, estabelecendo

${ }^{15}$ In MICK, Jacques e LIMA, SAMUEL. O Perfil do Jornalista Brasileiro. Florianópolis: Insular, 2013. 
para os Estados membros um compromisso mínimo com os direitos humanos das mulheres ${ }^{16}$. As conferências apontam que a desigualdade de gênero impede que as mulheres tenham a plenitude de seus direitos fundamentais garantidos, ao mesmo tempo em que apontam para uma cultura da violência contra corpos feminilizados, ampliada se interseccionarmos raça e classe. Ou seja, em que pese que todas as mulheres, sem exceção, sofrem com a desigualdade de gênero, esta adquire conotações mais restritivas e violentas conforme as mulheres sujeitas a ela.

Em trabalho anterior (LAGO, KAZAN e THAMANI, 2018), apontávamos que mesmo que as pesquisas em Jornalismo aparentemente aprofundassem uma relação com os estudos de gênero, estas ainda passavam mais ao largo de uma necessária perspectiva interseccional (CRENSHAW, 2002), apesar desta estar indicada em boa parte dos trabalhos que relacionam gênero e mídia em outros campos de conhecimento. Ancoradas especialmente em pesquisadoras negras (ALCOFF, 2016; DAVIS, 1990; GONZALES, 1981) defendemos que

A perspectiva interseccional aponta para a necessidade de se perceber, em cada momento ou aspecto analisado, o cruzamento de várias discriminações e opressões que incidem sobre os sujeitos. O exemplo mais claro, sempre evidenciado, é o das mulheres negras, que sofrem o racismo e o sexismo. (idem, p. 129)

16 Mais informações em: http://www.onumulheres.org.br/onu-mulheres/sobre-a-onumulheres/ 
Se é verdade que os estudos de gênero que pensam a mídia, a partir do campo da comunicação, geralmente não partem de uma perspectiva interseccional, no campo produtivo da mídia esta mirada é menos ainda cogitada. Assim, a maior parte do que vemos, assistimos, lemos, consumimos enfim, enfatiza sujeitos universais (homens ou mulheres), geralmente brancos, de uma determinada classe social, heterossexuais, conformados e singelamente adaptados aos padrões normativos de gênero.

Apesar disso, retomando a perspectiva de que a mídia não é um campo homogêneo, também podemos pensar nas fissuras, e outras possibilidades inscritas neste universo, que está constantemente em disputa, o que passo a discorrer a seguir.

\section{OUTRAS PALAVRAS}

Vivemos envoltos/as por um universo midiático que tende a reforçar perspectivas binárias, essencialistas,

que não apenas representa, mas opera a construção e circulação de representações de grupos, identidades, valores, com a visibilização de temas e sujeitos e invisibilização de outros. Que constrói versões naturalizadas de "homem/masculino", "mulher/feminino", das sexualidades possíveis e "corretas", das formas de viver aceitáveis -- e as não aceitáveis. Dos corpos "certos" e dos corpos desviantes, em todas as direções possíveis. E dos lugares aceitáveis para sujeitos e seus corpos, certos e errados (LAGO, KAZAN e THAMANI, 2018 p.125), 
No entanto, mesmo dentro deste universo podemos observar outras perspectivas, outras possibilidades, levadas a cabo por sujeitos outros/as, de lugares sociais diferentes. Apesar de todas as contradições que podemos atribuir às novas possibilidades levantadas pela internet (COULDRY e MEJIAS, 2019), ela desempenha um papel fundamental para a visibilidade de outros grupos sociais tradicionalmente alijados dos sistemas de expressão. E permite novas formas de organização e manifestação, como os feminismos de quarta onda (HOLLANDA, 2018) e seus movimentos nas mídias sociais. Movimentos, como os já mencionados \#metoo e \#primeiroassedio, com potencial de alavancar mudanças e também reações contrárias tópico importante mas que não poderei desenvolver neste artigo.

Mas não é apenas de campanhas massivas e intensas que vive a desnaturalização das hierarquias de gênero, relacionadas à internet. Uma profusão de veículos alternativos, como blogs, sites, portais, canais no youtube, podcasts, revistas online, filmes e etc, disponíveis para um público diverso têm oferecido outros olhares, questionando os privilégios e opressões relativos ao gênero, raça, sexualidade. Disputando espaço também com grupos que buscam reforçar o status quo e as normatividades, muitas vezes disseminando discursos de ódio (não podemos esquecer destes), estas iniciativas que constroem contranarrativas têm se popularizado e ampliado o escopo. São inúmeras e das mais variadas perspectivas e correntes, muitas organizadas a partir de lógicas de financiamento e gestão coletivas.

$\mathrm{Na}$ ficção é importante apontar para um campo bastante interessante, posto que é ainda um universo caracteristicamente ligado 
a uma visão do masculino, o do universo das histórias em quadrinhos ${ }^{17}$. Disputando com sistemas internacionais e industriais, há um crescimento de produções alternativas, muitas delas com propostas bastante inovadoras e questionadoras. É o caso do quadrinho Melaço ${ }^{18}$, produção alternativa de autoria de mulheres, que tematizam relações homoafetivas a partir de "good vibes", como indicam no lançamento do projeto de financiamento coletivo para o quadrinho ${ }^{19}$.

No campo da não ficção, temos diversos coletivos que se dispõem a oferecer alternativas às narrativas binárias sexistas hegemônicas. É o caso, por exemplo, do coletivo Nós, Mulheres da Periferia, formado por jovens mulheres da periferia de São Paulo que lançam, em 2012, um manifesto no então Blog Mural (hoje Agência Mural de Jornalismo das Periferias) onde apontam para a invisibilidade e os estereótipos que cercam as mulheres da periferia na mídia, com uma perspectiva interseccional. Depois da receptividade do manifesto, lançam em 2014 o coletivo, com página no facebook e posteriormente um site jornalístico ${ }^{20}$, no qual:

A linguagem é acessível e o fio condutor é pensar as mulheres periféricas a partir da interseccção gênero,

${ }^{17}$ Tão importante que motivou o prefeito do Rio de Janeiro recentemente a tentar censurar um quadrinho que trazia na capa um beijo entre dois heróis masculinos...

18 Parte do quadrinho pode ser visualizado em https://tapas.io/episode/731507

${ }^{19}$ Em https://www.catarse.me/melaco

20 O artigo inicial é "Nós, Mulheres da Periferia" e está no link https://www1.folha.uol.com.br/paywall/signup.shtml?https://www1.folha.uol.com.br/f sp/opiniao/29772-nos-mulheres-da-periferia.shtml .O site do coletivo pode ser acessado em http://nosmulheresdaperiferia.com.br/ 
raça, classe e território. Tanto no site quanto nas redes socias, veiculam artigos embasados em depoimento de moradoras da periferia e em suas vivências, como também aritgos que relatam e divulgam eventos na periferia, a partir de olhares contextualizados. Além disso abrem espaços de escuta e visibilidade, permitindo que outras mulheres publiquem suas histórias (LAGO, GONÇALVES e KAZAN, 2019, p. 11)

O Nós, Mulheres da Periferia une-se a outros exemplares de uma imprensa feminista, fruto por sua vez de uma longa tradição que trouxe, especialmente nas décadas de 70 e 80, importantes veículos alternativos, como Brasil Mulher e Mulherio. Organizados a partir da internet, estes novos veículos alternativos feministas mantêm também a tradição de serem não apenas veículos, mas organizações coletivas.

É o caso do Think Olga, ONG feminista criada em 2013, "com o objetivo de empoderar mulheres por meio da informação", como consta em seu site ${ }^{21}$, dentro da perspectiva que "informação é poder" e que é necessário quebrar as lógicas hegemônicas e propiciar espaços de fala e de exposição de conhecimentos. Dela saíram as famosas campanhas \#chegadefiufiu, em 2013, que viralizou a discussão sobre a naturalização do assédio no Brasil, tendo produzido um documentário de mesmo nome e a \#primeiroassedio, em que mulheres passaram a relatar a primeira vez em que foram assediadas. Lançada em 22 de outubro 2015, uma quinta-feira, no domingo a \# já tinha 82 
mil tweets que escancaravam o assédio como sendo feito em casa, em meninas pequenas (a média do primeiro assédio é em meninas de 9,7 anos, segundo a ONG). A Think Olga produz conteúdo diverso sobre questões de gênero, incluindo manuais de boas práticas para jornalistas e empresas de mídia.

Atuando como portais de informação e notícias, existem outros importantes espaços, como o Gênero e Número, startup e organização independente de mídia, que produz jornalismo de dados com o objetivo de subsidiar e visibilizar "dados e evidências relevantes para o debate sobre equidade de gênero por meio de diferentes produtos"22 e a Agência Patrícia Galvão ${ }^{23}$, com produção de conteúdo e realização de pesquisas em nível nacional, além de outros projetos.

Mais significativo ainda é o portal Geledés, do Instituto da Mulher Negra, que desde 1988 “se posiciona em defesa de mulheres e negros por entender que esses dois segmentos sociais padecem de desvantagens e discriminações no acesso às oportunidades sociais em função do racismo e do sexismo". ${ }^{24} \mathrm{Na}$ linha de frente de uma perspectiva interseccional, idealizado pela importantíssima intelectual negra Sueli Carneiro, o portal produz e divulga notícias, além de inúmeros outros projetos, sempre apontando para a junção raça e gênero.

Com uma proposta um pouco diferente, constituída enquanto uma revista on line, é importante destacar a AzMinas, que se coloca como um veículo jornalístico independente. Também fruto

\footnotetext{
${ }^{22}$ In http://www.generonumero.media/institucional/

${ }^{23}$ In https://agenciapatriciagalvao.org.br/quem-somos/

${ }^{24}$ In https://www.geledes.org.br/geledes-missao-institucional//
} 
de um instituto sem fins lucrativos, produz a revista digital além de app de enfrentamento à violência doméstica, palestras e consutorias ${ }^{25}$. A revista digital, propõe-se a falar de temáticas variadas (como as tradicionais voltadas para o público feminino), a partir de eixos de produção que incluem, entre outros, respeito, empatia, diversidade, leveza, independência editorial, linguagem acessível, etc. ${ }^{26}$. Jornalismo de mulheres, para mulheres, engajado contra o machismo ${ }^{27}$.

Um jornalismo a serviço da igualdade de gênero, apesar de muito mais evidente nas produções alternativas, também está sendo pensado junto ao mainstream midiático.

O fio condutor dessa perspectiva, que tem sido apontada por pesquisadoras/es que pensam as articulações entre gênero e jornalismo, inicia pela contestação de pressupostos do jornalismo tradicional, como o da objetividade. A BJR, revista da Associação Brasileira de Pesquisadores em Jornalismo (SBPJor), produziu recentemente um número especial sobre Gênero e Estudos de Jornalismo ${ }^{28}$, em que, além dos diagnósticos sobre como a mídia enquadra, invisibiliza e estereotipa mulheres e sujeitos que não se adequam à heterocisbranconormatividades, aponta para outras possibilidades.

\footnotetext{
25 In https://azmina.com.br/sobre/quem-somos/

${ }^{26}$ In https://azmina.com.br/missao-visao-e-valores/

27 A lista de produções independentes nesta linha é muito mais variada e inclui também um contingente expressivo de blogueiras, youtubers, etc, difícil de ser mapeado por seu alcance regional, de nicho, etc.

${ }^{28} \mathrm{In}$ https://bjr.sbpjor.org.br/bjr/issue/view/51
} 
Dois textos em especial contemplam esta perspectiva, "O feminino no livro de repórter" (MAROCCO e SILVA, 2016) e "Signo da relação e os desafios das narrativas jornalísticas sobre as LGBT" (GONÇALVES e MEDINA, 2016). Não à toa, olham para livros reportagem, formatos em que há uma possibilidade autoral maior. E, também não à toa, olham para pistas deixadas por jornalistas mulheres em livros autorais. Apesar das propostas e enquadramentos distintos, os dois trabalhos apontam para algumas similaridades: narrativas sensíveis, que incorporam a subjetividade e que tentam estabelecer diálogos com os sujeitos retratados.

Em certo sentido, fazem eco a outros artigos (BARBOSA e VARÃO, 2016; STOCKER e DALMASO, 2016) que questionam as noções de objetividade e neutralidade, pilares do jornalismo padrão que, nada mais fazem do que investir de neutralidade e objetividade a perspectiva universalizante do privilegiado. Ao propor trazer para a arena narrativa a experiência de mulheres e/ou sujeitos dissidentes às normas, estabelecem a necessidade de um jornalismo que sirva a estes sujeitos, que faça outras perguntas e proponham outros enquadramentos, assumindo que jornalistas e sujeitos narrados são seres situados, que têm que ser falados respeitando-se e a partir de seus lugares, como já indicava Haraway (1995) ao pensar a narrativa científica.

\section{PARA FINALIZAR}

A mídia constrói e faz circular narrativas, discursos, representações generificadas, geralmente a partir de lógicas 
heterossexistas, binárias discriminatórias em relação a sujeitos que não são a norma, esta totalmente excludente pois hierarquiza a partir do que é construído como o melhor: homens, brancos, hetero, cis e das camadas com maior poder aquisitivo. Estas normatividades, também por conta das relações que estabelecemos com a mídia e com as demais tecnologias de gênero, estão introjetadas na sociedade e reforçam a necessidade dos corpos se enquadrarem em caixinhas por demais estreitas.

Mas a vida segue e, por mais que exista a pressão para o enquadramento, existem sujeitos vivos/as, pulsantes, que vivem e que resistem, muitas vezes só por existir. Este movimento se reflete também nos sistemas midiáticos, palcos de disputas constantes de sentido. Em batalhas cotidianas que todos/as nós, que estamos imersos dentro deste continuum não podemos deixar de travar. Seja produzindo, seja consumindo, apoiando e/ou divulgando experiências outras que apontem para a complexidade da vida humana - e não para sua redução aniquiladora.

\section{REFERÊNCIAS}

ALCOFF, Linda. Uma epistemologia para a próxima revolução. Sociedade e Estado. Brasília, n.1,v.31,jan./abr.,2016. Disponível em: $<$ http://periodicos.unb.br/index.php/estado/article/view/21425/15326 $>$.

BARBOSA, K; VARÃO, R. Erro, dúvida e jornalismo generificado: Um olhar sobre a cobertura de estupro a partir da reportagem "A rape on 
campus". Brazilian Journalism Research, v. 14, n. 1, p. 12-29, abril 2018.

Disponível em https://bjr.sbpjor.org.br/bjr/article/view/1049/pdf 1 DOI: https://doi.org/10.25200/BJR.v14n1.2018.1049

BOURDIEU, Pierre. Coisas Ditas. São Paulo: Brasiliense, 1990.

A dominação masculina. São Paulo: Bertrand Brasil, 2019 (15a edição).

COULDRY, Nick e MEJIAS, Ulises. The costs of connection: how data is colonizing human life and appropriating if for capitalism. Reedwood City: Stanford University Press, 2019.

CRENSHAW, KIMBERLÉ. Documento para o Encontro de Especialistas em Aspectos da Discriminação Racial Relativos ao Gênero. In: Revista Estudos Feministas, v. 10, n.1, pp 171-188. Florianópolis:UFSC, 2002

DAVIS, Angela. Mulheres, Raça e Classe. São Paulo: Boitempo. 2016

GONÇALVES, Gean; MEDINA, Cremilda. Signo da relação e os desafios das narrativas jornalísticas sobre as LGBT. Brazilian Journalism Research, v.14, n.1, p. 56-77, abril 2018. ISSN 1981-9854. Disponível em: https://bjr.sbpjor.org.br/bjr/article/view/1066/pdf 1 DOI: https://doi.org/10.25200/BJR.v14n1.2018.1066. 
GONZALEZ, Lélia. Racismo e sexismo na cultura brasileira, in Psicanálise e Política. Rio de Janeiro, C. S. P. K. Kemper. 1981

HALL, Stuart. A identidade cultural na pós-modernidade. Tradução de Tomaz Tadeu da Silva e Guacira Lopes Louro. Rio de Janeiro: Lamparina, 2015.

HARAWAY,D. (1995). Saberes localizados: a questão da ciência para o feminismo e o privilégio da perspectiva parcial. Cadernos Pagu 5, Campinas: Ed. Unicamp, vol. 5, pp. 7-41

HOLLANDA, Heloisa Buarque de. A Explosão Feminista. São Paulo: Cia. Das Letras, 2018.

SCOTT, Joan. Gênero: uma categoria útil de análise histórica. In Revista Educação e Realidade, Porto Alegre: UFRGS, vol 20 no 2, jul/dez, 1995, pp 71-99

LAGO, Cláudia, KAZAN, Evelyn e THAMANI, Manuela. Jornalismo e estudos de gênero: e a interseccionalidade, onde está? In: AGUIAR, Leonel, SILVA, Marcos Paulo da e MARTINEZ, Monica (orgs). Desigualdades, Relações de Gênero e Estudos de Jornalismo. São Paulo: Intercom, 2018. Disponível para dowloud em https://drive.google.com/file/d/1m4icSBgkmvwTlklgpOPSOMkt4gRx $\underline{\text { 0bx8/view }}$ 
LAGO, Cláudia, GONÇALVES, Gean e KAZAN, Evelyn. Jornalismo na lógica descolonial: o caso do Nós, Mulheres da Periferia. Trabalho apresentado ao 17o Encontro da SBPJor. Goiânia, novembro de 2019.

LAURETIS. A tecnologia de gênero. In: HOLANDA, Heloisa Buarque de (Org.). Tendências e impasses: o feminismo como crítica cultural. Rio de Janeiro, Rocco, 1994. p. 206-242

MAROCCO, Beatriz; SILVA, Marcia Veiga da. O feminino no "livro de repórter": uma mirada epistemológica de gênero sobre as práticas jornalísticas. In Brazilian Journalism Research, v.14, n.1, p.30-53, abril 2018.

Disponível em: https://bjr.sbpjor.org.br/bjr/article/view/1029/pdf 1

STOCKER, Pâmela Caroline; DALMASO, Silvana Copetti. A cultura do estupro entra na pauta: a disputa de sentidos entre jornalismo e leitores do Diário Gaúcho. In Brazilian Journalism Research, v.14, n.1, p. 256-281, abril 2018.

Disponível em: https://bjr.sbpjor.org.br/bjr/article/view/1025/pdf 1 . DOI: https://doi.org/10.25200/BJR.v14n1.2018.1025. 